\title{
The role of empowerment in the use of modern contraceptives among women in need of family planning in Burkina Faso: A multilevel analysis
}

\section{Sylvain Y. M. SOME}

National Yang-Ming University, Institute of Public Health https://orcid.org/0000-0003-3492-305X Christy Pu

National Yang-Ming University, Institute of Public Health

Song-Lih Huang ( $\square$ songlih@gmail.com )

National Yang-Ming University, Institute of Public Health https://orcid.org/0000-0002-5758-2975

\section{Research}

Keywords: Gender equality, women's empowerment, family planning, Burkina Faso

Posted Date: March 18th, 2020

DOI: https://doi.org/10.21203/rs.3.rs-17908/v1

License: (c) (i) This work is licensed under a Creative Commons Attribution 4.0 International License.

Read Full License 


\section{Abstract}

Background In Burkina Faso, women still have difficulty satisfying their family planning demand because of the patriarchal and gender-unequal society. Despite evidence that women's empowerment can help, few studies have measured its impact at both community and household levels. Taking into account these two parameters, we looked into the association between women's empowerment and modern contraception use among Married Women of Reproductive Age (MWRA) with no desire for having children in Burkina Faso. Methods Using the 2010 Demographic and Health Survey (DHS), we analyzed data from 4714 MWRA with family planning needs from 573 communities. Indicators of gender equality at the community level were composed of aggregated variables for each primary sampling unit, and domains of women's agency in households matters were derived with principal component analysis. A multilevel logistic regression model was used to gauge the effects of empowerment on modern contraceptives use adjusted for household socioeconomic status and demographics of women. Results Among MWRA, $30.8 \%$ satisfied their demand for family planning using modern methods. At the community level, higher women's assets ownership (aOR 1.26, $\mathrm{Cl} 1.04$ - 1.54), secondary education (aOR 1.45 , OR $1.08-1.64$ ), and exposure to family planning messages (aOR 1.33, $\mathrm{Cl} 1.08-1.64$ ) were associated with more modern contraceptive use; higher ideal number of children was negatively associated (aOR 0.76, $\mathrm{Cl} 0.61$ - 0.95). Unexpectedly, higher community prevalence of female genital mutilation was positively associated with contraceptive use (aOR 1.25, $\mathrm{Cl} 1.03-1.52)$. Women's agency in household matters, including opposing domestic violence, involved with decisions and enjoying freedom in seeking healthcare were positively associated with use, but only the last domain remained significant in multilevel analysis (aOR 1.29, Cl 1.08 - 1.54). Living in richer household, being older, and having secondary education level were also positively associated with modern contraceptive use. Conclusion Gender equality at the community level and women's situation in the household constitute the context in which women's demand for family planning is determined. Therefore, promoting gender equality and ensuring women's entitlement to make life choices have the potential to increase modern contraceptive coverage along with improved life conditions.

\section{Background}

Around 125 million African women of reproductive age wanted to avoid unwanted pregnancies in 2017; however, around $47 \%$ of these women either only used traditional methods or didn't use any contraceptive methods at all [1]. Considered to have an unmet need for modern contraception, these women accounted for $90 \%$ of all unintended pregnancies in Africa [2]. The proportion of African women with unmet need for modern contraception remains high, particularly in West Africa region where it was estimated at $25.4 \%$ in 2010, twice more than that of the global level [3]. Meanwhile, demand for family planning satisfied using modern contraceptive which represents modern contraceptive coverage among those in-need was the lowest (33\%) in West and Central Africa among married women of reproductive age (MWRA), compared with other least developed regions (53\%) [4]. In Burkina Faso, a West African country, this proportion grew from $20 \%$ in 1990 to $36 \%$ in 2010, but is still far from the Sustainable Development Goals (SDGs) 
benchmark of at least 75\% by $2030[3,5]$. Consequently, women in Burkina Faso disproportionately suffer from inability to use modern contraceptives to prevent unintended pregnancies.

In many African countries, poor socioeconomic development, social barriers, and weak family planning programs often limit women's ability to access modern contraceptives. For instance, in Burkina Faso, the major reasons for not using family planning (FP) methods included lack of access and lack of knowledge, partners' opposition to the practice, and health concerns about contraceptive methods [6]. Over the past decade, the Millennium Development Goals (MDGs) made significant progress to reduce poverty and expand the use of contraceptives. Yet from 1990 to 2015 in West Africa, the amount of unmet needs for family planning persistently exceeded contraceptive prevalence $[3,7]$. Therefore, removing social barriers that limit women's contraceptive use could help maintain progress made during the MDG-era and make greater achievement under the SDGs. Therefore, it is crucial to better understand gender-based norms and how women's empowerment influences women's contraceptive behavior.

\section{Gender norms, women's empowerment and contraceptive use}

According to the United Nations, gender norms are social institutions that define masculinity and femininity based on sex and ascribe to male and female roles, relationships and behaviors deemed to be appropriate [8]. In patriarchy, the social system is governed by gender rules in which the male as breadwinner is not only the predominant owner of resources but also the primary holder of decisionmaking power relative to the female housekeeper [9]. As a result, this social construction of roles and identities guide sex attitudes, behaviors, and values which inexorably lead to gender inequality and imbalance power dynamic in households. The promotion of gender equality and the empowerment of women are therefore a necessary step for women to gain control over their sexuality and reproduction rights. In fact, gender equality refers to both male's and female's equal access to resources, opportunities, rights and protections [10]. As for empowerment, it is a process that expands one's ability to make choices and act upon them against prevailing social norms; it involves access to resources and the exercise of agency to transform choices into desired goals [11]. Agency is a central part of empowerment and is exercised across multiple dimensions of life. Research shows that different domains of women's agency are positively associated with contraceptive use, but depending on each setting and domain as well as contraceptive measure $[12,13]$. Empowering women remains key to preventing unintended pregnancies in SSA, yet community level interventions and direct contraceptive provision rarely translate into downstream modern contraceptive prevalence [14].

Research suggests that gender norms may influence women's ability to use contraceptives through increase in gender equity and women's empowerment [15]. However, a critical research gap exists on conceptualizing empowerment at different levels and domains, especially Africa [16, 17]. To our knowledge, only two studies in SSA setting adopted a comprehensive approach to examine the link between multiple domains of women's empowerment and contraceptive use at country, community and household levels. The first study found, across 32 SSA countries, positive association between women's empowerment and contraceptive use in countries with greater development indices, neighborhoods with 
greater socioeconomic position for women, and households with equitable gender norms [18]. The second showed in urban Nigeria that increased participation in household matters was individually and collectively associated with modern contraceptive adoption and consistent use [19]. Yet, none of these recent studies drew on current SDGs framework set by the global community for universal access to sexual and reproductive health and reproductive rights [20]. More specifically, two aspects in the SDGs are relevant to family planning. The first aspect, which is an SDG indicator (3.7.1) for monitoring family planning outcome, represents the proportion of women who have their need for family planning satisfied by modern methods. It represents from gender perspective the extent to which women who need family planning are covered by using modern methods. The second outlined pathways to achieve gender equality and women's empowerment by ending discrimination and violence and by promoting access to rights and opportunities. Accounting for SDGs indicators would then facilitate track progress and help design more effective family planning programs that integrate gender equality and women's empowerment. Furthermore, none of the previous studies used rigorous methods to identify domains of agency prior to their analysis. Using exploratory and confirmatory analyses, Yount et al. found that women may exercise agency in family decisions, freedom of movement, and attitudes about violence against wives domains [21]. Yet, it remains unclear which domains and which levels of empowerment are relevant to modern contraceptive coverage in a specific setting. In this study, we assessed women's inability to use modern contraceptive methods and its link with women's empowerment indicators in households and communities in a West African setting.

\section{Conceptual framework}

In our conceptual framework, we adapted Kabeer's framework of empowerment to consider access to resources and agency as explanatory variables that enable the use of modern contraceptives among women in-need [11]. Access to resources refers to the targets set in goal 5 of the 2030 Development Agenda to achieve gender equality and empower all women and girls [20]. These targets include ending discrimination and violence against all women and girls and promoting their rights and opportunities. Indicators of these targets measured the levels of domestic violence, early marriage, female genital mutilation, unpaid employment, and those of assets ownership, education, number of children, exposure to FP messages, and access to FP health worker. Women's agency reflects on women's involvement in different domains of household matters including family decisions and freedom of movement and attitudes toward domestic violence [21].

Furthermore, we adjusted for socioeconomic and demographic factors known to be related with contraceptive use [16]. Therefore, we argued that gender equitable norms in communities and households would increase modern contraceptive prevalence among in-need women. More specifically, lower discrimination and violence, greater rights and opportunities in communities as well as participation in family decisions, freedom of movement and opposition to domestic violence in households would enable women to use modern contraceptives. The conceptual framework is illustrated by the diagram in Figure 1. 


\section{Data Collection And Methods}

\section{Context}

Burkina Faso is a predominantly rural country of estimated 20 million inhabitants in 2020 with a 3.1\% population growth rate per year [22]. It is a primarily patriarchal country in which women's childbearing roles and subordinate conditions are part of the social fabric [23]. In 2018, Burkina Faso was among countries with the lowest human development index and the highest gender inequality index in West Africa [24].

\section{Data source}

The data for this study came from the individual women file of the 2010 Burkina Faso Demographic and Health Survey (DHS) [25]. This is the most recent nationally-representative and complete householdbased data collected on family planning, women's empowerment, and household characteristics.

The DHS used a stratified two-stage cluster design. At the first stage, 574 Enumeration Areas (EA) were selected using the Probability Proportional to Size (PPS) sampling method based on the 2006 population census. However, one EA located in the Sahel region was not surveyed. At the second stage, a total of 14,424 households were selected using systematic random sampling based on a list of households in each EA. Within each selected household, all eligible women aged 15-49 years were interviewed. In sum, data from 573 out of 574 clusters, 14242 out of 14536 households, and 17087 out of 17363 women were produced resulting in response rates of $99.8 \%, 99.2 \%$ and $98.4 \%$ at cluster, household and individual levels.

\section{Population}

Our focus was on MWRA at risk of pregnancy (fecund) and who desired to limit or delay fertility by at least 2 years. We also included pregnant and postpartum amenorrhoeic women who mistimed, unplanned or did not want their current pregnancy or recent childbirth. After removal of missing values, the final unweighted study population size was 4714 MWRA, living in 573 communities, and in need of FP (Figure 2).

\section{Outcome and exploratory variables}

In the DHS recode manual, modern contraceptive methods are female and male sterilization, contraceptive pills, intrauterine contraceptive devices, injectables, implants, female and male condoms, diaphragm, contraceptive foam and jelly, lactational amenorrhea method, standard days method, two-day method, emergency contraception, cervical cap, and contraceptive sponge [25]. The respondents were asked two questions. First, "Are you currently doing something or using any method to delay or avoid getting pregnant?" If the answer was yes then we would follow up with the second question: "Which method are you using?" We coded " 1 " when women were using any modern contraception methods and " 0 " if otherwise. 
Our main exposure variable is women's empowerment measured at both community and household levels. In this study, community-level indicators were aggregated data computed for each EA using data of all women in that EA. Norms that favored violence and discrimination against women were measured by the proportions of acceptance of domestic violence, early marriage (before 18 years old), female genital mutilation, and unpaid employment. Meanwhile, norms that promote women's rights and opportunities were measured by the proportions of women's assets ownership, exposure to family planning messages, access to family planning health workers, years of education, and ideal number of children. Women's agency in their households was represented by three variables: women's attitudes toward domestic violence, participation in decision making, and freedom in seeking medical services. The three variables were constructed based on twelve questions. The categorization and codification are shown in Table 1.

Household socioeconomic characteristics (wealth and residence in rural or urban areas), and women's sociodemographic factors (age and education) were used as control variables.

\section{Reliability of women's agency}

The responses to the 12 questions in Table 1 were examined for internal consistency by Principal Components Analysis (PCA) and Cronbach's alpha. Since PCA is sensitive to relative scaling, we then used original categorization from the survey and identified three constructs of women's agency using 0.300 as the cut-off value [26]. After that, Cronbach's alpha was applied scaled responses to assess their inter-item reliability for each specific construct; we used 0.65 as a minimum reliability cut-point [27]. The scaling was used to differentiate "empowered" from "not empowered" women. For instance, women who did not justify wife beating, those who had a say in household decisions, and those who did not find problem in getting medical help were considered as empowered. Finally, drawing from previous studies, summative scales were constructed to reflect greater women's agency in a specific domain [28]. For attitudes toward domestic violence, a woman was given a score of 1 if she responded with 'no' to all five DHS questions (greater agency) and 0 if she responded 'yes' (subordination) to any question.

Involvement in household decision-making was based on women's say in family visits, own health care, or household purchases. A score of 1 was given if she 'solely or jointly with the husband' participated (greater agency) and 0 if 'husband alone, someone else or other' made the decision (exclusion). In freedom of movement to seek healthcare, we based our analysis on constraints to access healthcare and coded 1 if a women faced no constraint (autonomy) and 0 if she faced constraint (dependency) in each of the following situations: permission to go, money needed for treatment, distance to the health facility, or not wanting to go alone (Table 1).

\section{Data analyses}

We performed descriptive and bivariate analyses and fitted multilevel logistic regression models adjusted for weights accounting for cluster-effect and non-response. All analyses were conducted using Stata version 14 [29]. 
Firstly, we described frequencies and probability distributions of community-level indicators of gender equality, women's agency, as well as household socioeconomic status and women's sociodemographic characteristics. For community indicators, values higher or lower than national means were regarded as "high" or "low". Then, we assessed the relationship between these independent variables and modern contraceptive prevalence using Chi square. Prior to the regression analysis, we ensured that there was no multicollinearity using a less than five $(<5)$ Variance Inflation Factor (VIF) as a threshold. In the multilevel logistic regression analysis, the null model showed an Intra-Cluster Correlation (ICC) of $20 \%$. Three models were built to estimate predictors of modern contraception use. Model 1 analyzed the effect of women's agency domains on contraceptive use. Model 2 added community indicators of gender equality, including those reflecting violence and discrimination against women and promotion and women's rights and opportunities. Model 3 further added household socioeconomic status and women's sociodemographic factors.

\section{Ethical considerations}

The proposed analysis was exempt as described in the enforcement rules issued by the Institutional Review Board of National Yang-Ming University.

\section{Results}

\section{Sample characteristics}

We found that among the 4714 women of reproduction with need for family planning, $66.9 \%$ were using no contraceptive methods at all, while $2.4 \%$ were using traditional methods. Among modern contraceptives users (30.7\%), 10.1\% and $20.6 \%$ were using short-term and long-term modern methods respectively. No use of permanent modern contraceptive methods was reported.

\section{Domains of women's agency}

Principal Component Analysis identified three domains of women's agency within the household setting: attitudes toward domestic violence, participation in household decisions, and freedom in seeking healthcare items (Table 2). Cronbach's alpha testing found that the coefficients for the three domains were $0.83,0.65$, and 0.69 respectively. Summative scales were built for each domain; higher scores reflected greater ability to oppose domestic violence, participate in household decisions, or seek healthcare.

\section{Bivariate analysis}

All three components of women's agency were significantly associated with modern contraceptive use in bivariate analysis (Table 3 ). Women who were strongly opposed to domestic violence, those who 
participated in household decisions, and those free in seeking healthcare had higher prevalence of modern contraceptive use.

We then examined whether indicators of gender equality at the community level were associated with modern contraceptives use. Two categories of indicators were examined: violence and discrimination against women, and promotion of women's rights and opportunities. All indicators of violence and discrimination against women were negatively and significantly associated with modern contraceptive use except genital mutilation, which was marginally significant. With regard to indicators of promotion of women's rights, positive association with modern contraceptive use was found in community prevalence of secondary education and exposure to FP messages.

At the household and individual levels, women who lived in rich households or in urban areas had higher levels of modern contraceptive use. Women in the higher age groups and those with higher education levels had also higher prevalence of modern contraceptive use.

\section{Regressions analysis}

Model 1 in the multilevel regression analysis included the three domains of women's agency, each showing significant positive association with contraceptive use (Table 4). Community-level indicators of gender equality were added in model 2 . Female genital mutilation, ideal number of children, secondary education for women, and exposure to FP messages were significantly associated with contraceptive use, with some attenuation in the risk estimates for women's agency domains. Model 3 included demographic factors, which further attenuated the risk estimates for women's agency, with marginal significance for two of the three domains. The estimates for community-level indicators of gender equality remained essentially the same, with living in higher community-level of assets ownership becoming significant.

Measures of variations in the null model show a substantial variation in contraceptive use across the 573 communities ( $\sigma 2=0.82,95 \% \mathrm{Cl} 0.64$ to 1.05 ), and $20 \%$ of the variation in contraceptive use was explained by community level indicators. Using log likelihood test to assess the model-fitting, model 2 showed a significant improvement in fit over Model 1 [ $\chi 2(9)=149.82 ; p<0.001]$, and model 3 over model 2: [ $\chi 2(7)$ $=101.80 ; p<0.001]$. The Proportions of Variance Change (PVC) measured the levels of variance in the communities explained by the introduction of exploratory variables. They were $14 \%, 55 \%$ and $60 \%$ in models 1,2 , and 3 ; respectively.

\section{Discussion}

Only $30.7 \%$ of married women of reproductive age in need of contraception were able to use modern methods to prevent or delay unintended pregnancy in Burkina Faso. We analyzed women's empowerment at two levels: women's agency within the household setting, and gender equality at the community level. Both were found to be significantly associated with modern contraceptive use. More specifically, at 
community-level, women's rights and opportunities were positively associated with the use of modern methods of contraception while violence and discrimination against women had the opposite effect, with the exception of female genital mutilation. The association was mostly maintained after adjustment for socioeconomic and demographic variables.

\section{Entitlements to make life choices}

In this study, each domain of women's agency was positively related to modern contraceptive use. Similarly, a review found positive relationship with contraceptive use in studies that measured agency as separate domains of decision-making and freedom of movement [12]. Additionally, Bongale et al. found that having gender equitable attitudes was a significant determinant of decision-making power related to women's use of modern contraceptive methods [30]. In patriarchal societies, men are responsible for fertility decisions as they assume the position of household heads; conversely, women are assigned child care and household chores. This traditional division of labor and spousal power imbalance indicates the importance of women's participation in household decisions [31]. Okigbo et al. found that changes in gender norms toward equitable attitudes and household decision-making participation increased women's modern contraceptive use in urban Nigeria [19]. However, the relationship between domains of agency and modern contraceptive use is not consistent, and may depend on other factors such as living conditions and the effectiveness of family programs. For instance, within domains of empowerment and modern contraceptive use, Do et al. found no relationship with attitudes toward domestic violence and freedom of movement in Zambia, Ghana, Namibia and Uganda [13]. However, for decision-making power, no relationship was found in Zambia and Ghana, but Namibia and Uganda. Besides, Bogale et al. found a positive relationship between decision-making power and contraceptive use among rural women but no relationship among urban women [30]. These inconsistencies and mixed results may also stem from discrepancies in the measurement of agency domains, the use of reference category, the study settings, and women's socioeconomic status [12].

In the present study, we tried to display the importance of women's agency by multilevel analyses taking into account both the community norms (as represented by community indicators of gender equality) and socioeconomic status. We found that the persistence of positive relationships among women, particularly their ability to freely seek healthcare, may have revealed a critical domain of agency for contraceptive use in the Burkina Faso setting. A previous study found that married women in Burkina Faso used various bargaining strategies to achieve their objective when seeking healthcare [32]. This domain has the most direct relationship with women's ability to seek help with regard to family planning.

\section{Gender norms at the community-level}

Consistent with the socioecological framework, we found that gender equality norms at community-level shape modern contraceptive use [33]. Although the DHS did not directly measure norms on gender equality, in this study we used aggregated data of women's status in each sampling area as indicators. Specifically, higher levels of women's rights and opportunities increased modern contraceptive use, while higher levels of violence and discrimination had the opposite effects. These findings are supported by 
previous evidence that traditional gender norms that support higher ideal number of children, early marriage, domestic violence or female unemployment reduced women's ability to meet their family planning needs [34-36]. Also, promoting women's education, autonomy, HIV knowledge, and contact with family planning health workers were shown to increase modern contraceptive use among women $[34,35$, 37]. In patriarchal societies, violence and discrimination are used to maintain women in a socially disadvantaged position and legitimize their subordinate position [38]. Prevailing fertility norms set women's role as mothers and wives by valuing early marriage and high fertility while overlooking their socioeconomic independence [39]. In contrast, the promotion of women's access to means of production, human capital and family planning knowledge contributed to challenging high fertility preferences through life choices. One unexpected finding was that the prevalence of female genital mutilation was associated with higher likelihood of modern contraceptive use. The possibility of ecological fallacy was ruled out by including individual data on genital mutilation in the model (not shown). One study suggested that in communities with more mutilated women, negative obstetrical consequences of high fertility may be more appreciated [40].

Previous studies have found that at the country-level, greater socioeconomic opportunities for women were associated with increased uptake of modern contraceptive use $[3,18,41]$. This study demonstrated that within a specific country, this relationship holds true even after adjusting for individual socioeconomic variables. This finding indicates the importance of creating a gender-equal environment in the community.

\section{Demographic factors}

We found that the probability of modern contraceptive use increases with women's higher socioeconomic position. Education and economic position were known to be key factors of contraceptive use in SubSaharan Africa [16]. These variables may be associated with greater access to and acceptability of modern contraceptives. Besides, previous research in Burkina Faso showed that greater socioeconomic position contribute to participation in household decisions which may include modern contraceptive use [42]. In fact, we found that household wealth, urban residency, and women's education were significantly and positively associated with opposition to domestic violence, influence on household decisions, and freedom in seeking healthcare (Data not shown). However, by comparing the models in Table 4, it is suggested that women's agency played some additional roles that are independent from women's individual factors, although two of the three domains showed only marginal significance. To fully appreciate the relationship between household income, women's education, and women's agency in family planning, we need information from the male counterpart in decision making, as well as narratives from female participants.

This study used a grounded conceptual framework, systematic analytical strategy, and rigorous statistical methods to assess modern contraceptive use and its link with women's empowerment. Nonetheless, we acknowledge several limitations. Due to data limitation on the family planning service environment, we were unable to assess the role of the quality and delivery of health services. Likewise, 
the DHS questionnaire on women's empowerment was based on a conceptual framework developed from experience in Asia rather than Africa [43]. Some restrictions found to women's empowerment may not be relevant to our context. Therefore, qualitative research is needed to understand context surrounding domains of empowerment for the sake to identify appropriate indicators and get accurate measures. Nevertheless, our analytical strategy using principal components analysis and Cronbach's alpha was able to identify with satisfactory consistency three domains of women's agency that are similar to previous validated models for women's agency [21]. Another major limitation is the cross-sectional nature of the study design that prevented us from making any causality inference on the relation between women's empowerment and modern contraceptives use. Lastly, the use of aggregated data to measure community-level indicators of empowerment may have biased our results, as the concept of community goes beyond geographical boundaries of enumeration areas [44].

This study has strengths as it outlined the role of community-level gender equality and women's agency in households in modern contraceptive use in Burkina Faso. First, we not only conceptualized empowerment at individual and community levels, but we also distinguished domains and indicators at both levels. Doing so would facilitate the design of interventions targeting specific levels of action and populations of interest. Unlike previous studies, we focused on modern contraceptive use among women with no childbearing desire. This indicator is of great significance as it tracks progress toward universal access to sexual and reproductive health and reproductive rights $[45,46]$. Since 2012, Burkina Faso is committed to increasing modern contraceptive uptake among women and girls. The results of this study would help better understand gender norms influences on modern contraceptive coverage which could result in the integration of change in gender norms in communities and households to achieve long-term family planning effectiveness together with sexual and reproductive rights.

\section{Conclusion}

In the patriarchal social system, structural inequality and household subordinate position limit women's empowerment to participate in life choices, including modern contraceptive use. Therefore, promoting gender equality in communities and ensuring the exercise of agency in household matters could contribute to enable women to satisfy their demand for family planning using modern methods. In order to achieve the SDGs' target of universal access to sexual and reproductive health services, substantial effort should be directed toward gender-equitable norms and relationships in all spheres of life, including communities and homes. Meanwhile, financial and technical resources are needed to increase family planning access and acceptability, involve male partners and seek community support for the fulfillment of reproductive rights.

\section{Abbreviations}

MWRA

Married Women of Reproductive Age

DHS 
Demographic and Health Survey

SDGs

Sustainable Development Goals

MDGs

Millennium Development Goals

FP

Family Planning

PCA

Principal Components Analysis

ICC

Intra-Cluster Correlation

PVC

Proportions of Variance Change

\section{Declarations}

\section{Ethics approval and consent to participate}

Not applicable

\section{Consent for publication}

Not applicable

\section{Availability of data and materials}

The data supporting the findings of this research are publicly available from the DHS Program in https://dhsprogram.com/

\section{Competing interests}

The authors declare that they have no competing interests.

\section{Funding}

Not applicable

\section{Authors' contributions}

SYMS contributed to the selection of the study hypotheses, questions, data analysis and the drafting of the first report

SYMS, CP and SLH contributed to the interpretation of data, the revision of the report and the approval of the final version. All authors were involved in the writing of the paper, and they all approved the final 
submission

\section{Acknowledgements}

The authors would like to thank the Editors-in-Chief and the reviewers for their comments and suggestions to improve the quality of this paper

\section{References}

1. Darroch JE, Sully E, Biddlecom A: Adding It Up: Investing in Contraception and Maternal and Newborn Health, 2017-Supplementary Tables. New York, NY: The Guttmacher Institute 2017.

2. Ameyaw EK, Budu E, Sambah F, Baatiema L, Appiah F, Seidu A-A, Ahinkorah BO: Prevalence and determinants of unintended pregnancy in sub-Saharan Africa: A multi-country analysis of demographic and health surveys. PLoS One 2019, 14(8).

3. Alkema L, Kantorova V, Menozzi C, Biddlecom A: National, regional, and global rates and trends in contraceptive prevalence and unmet need for family planning between 1990 and 2015: a systematic and comprehensive analysis. Lancet 2013, 381.

4. Ewerling F, Victora CG, Raj A, Coll CVN, Hellwig F, Barros AJD: Demand for family planning satisfied with modern methods among sexually active women in low- and middle-income countries: who is lagging behind? Reproductive Health 2018, 15(1):42.

5. Choi Y, Fabic MS, Hounton S, Koroma D: Meeting demand for family planning within a generation: prospects and implications at country level. Global health action 2015, 8(1):29734.

6. Sedgh G, Hussain R: Reasons for contraceptive nonuse among women having unmet need for contraception in developing countries. Stud Fam Plann 2014, 45(2):151-169.

7. Nations U: The millennium development goals report. New York: United Nations 2015.

8. Women U: Concepts and definitions. UN Women 2013.

9. Walby S: Theorizing patriarchy: Basil Blackwell; 1990.

10. Grown C, Gupta GR, Kes A: Taking action: achieving gender equality and empowering women: Earthscan; 2005.

11. Kabeer N: Resources, agency, achievements: Reflections on the measurement of women's empowerment. Development and change 1999, 30(3):435-464.

12. James-Hawkins L, Peters C, VanderEnde K, Bardin L, Yount KM: Women's agency and its relationship to current contraceptive use in lower-and middle-income countries: A systematic review of the literature. Global public health 2018, 13(7):843-858.

13. Do M, Kurimoto N: Women's empowerment and choice of contraceptive methods in selected African countries. International perspectives on sexual and reproductive health 2012:23-33.

14. Phillips SJ, Mbizvo MT: Empowering adolescent girls in Sub-Saharan Africa to prevent unintended pregnancy and HIV: A critical research gap. International Journal of Gynecology \& Obstetrics 2016, 132(1):1-3. 
15. Bertotti AM: Gendered divisions of fertility work: Socioeconomic predictors of female versus male sterilization. Journal of Marriage and Family 2013, 75(1):13-25.

16. Blackstone SR, Nwaozuru U, Iwelunmor J: Factors influencing contraceptive use in sub-Saharan Africa: a systematic review. Int Q Community Health Educ 2017, 37(2):79-91.

17. Prata N, Fraser A, Huchko MJ, Gipson JD, Withers M, Lewis S, Ciaraldi EJ, Upadhyay UD: Women's empowerment and family planning: A review of the literature. J Biosoc Sci 2017, 49(6):713-743.

18. Yaya S, Uthman OA, Ekholuenetale M, Bishwajit G: Women empowerment as an enabling factor of contraceptive use in sub-Saharan Africa: a multilevel analysis of cross-sectional surveys of 32 countries. Reproductive health 2018, 15(1):214.

19. Okigbo CC, Speizer IS, Domino ME, Curtis SL, Halpern CT, Fotso JC: Gender norms and modern contraceptive use in urban Nigeria: a multilevel longitudinal study. BMC Womens Health 2018, 18(1):178.

20. Desa U: Transforming our world: The 2030 agenda for sustainable development. 2016.

21. Yount KM, VanderEnde KE, Dodell S, Cheong YF: Measurement of women's agency in Egypt: A National Validation Study. Social indicators research 2016, 128(3):1171-1192.

22. GUENGANT J-P: THEME 16: PROJECTIONS DEMOGRAPHIQUES. 2009.

23. Poirier J, Guella G: Fondements socio-économiques de la fécondité chez les Mossi du Plateau Central (Burkina Faso): UERD; 1997.

24. Programme UND: Human Development Report 2019; 2019.

25. Program TD: Burkina Faso: Standard DHS. In.; 2010.

26. Tabachnick B, Fidell L: Using multivariate statistics 7th Edition. In.: Pearson; 2019.

27. Nunnally JC: Psychometric theory 3E: Tata McGraw-Hill Education; 1994.

28. Jennings $L, N a$, Cherewick M, Hindin M, Mullany B, Ahmed S: Women's empowerment and male involvement in antenatal care: analyses of Demographic and Health Surveys (DHS) in selected African countries. BMC Pregnancy Childbirth 2014, 14(1):297.

29. StataCorp L: Stata statistical software: release 14.[computer program]. StataCorp LP 2015.

30. Bogale B, Wondafrash M, Tilahun T, Girma E: Married women's decision making power on modern contraceptive use in urban and rural southern Ethiopia. BMC Public Health 2011, 11.

31. Connell RW: Gender and power. Palo Alto. CA: Stanford University Press Connell, RW (1993) The big picture: Masculinities in recent world history Theory and Society 1987, 22:597-623.

32. Nikièma B, Haddad S, Potvin L: Women Bargaining to Seek Healthcare: Norms, Domestic Practices, and Implications in Rural Burkina Faso. World Development 2008, 36(4):608-624.

33. Brofenbrenner U: The ecology of human development: Experiments by nature and design Harvard University Press Cambridge. In.: MA; 1979.

34. Metheny N, Stephenson R: How the community shapes unmet need for modern contraception: an analysis of 44 demographic and health surveys. Stud Fam Plann 2017, 48(3):235-251. 
35. Mutumba M, Wekesa E, Stephenson R: Community influences on modern contraceptive use among young women in low and middle-income countries: a cross-sectional multi-country analysis. BMC Public Health 2018, 18(1):430.

36. Elfstrom KM, Stephenson R: The role of place in shaping contraceptive use among women in Africa. PLoS One 2012, 7(7):e40670.

37. Zimmerman LA, Bell SO, Li Q, Morzenti A, Anglewicz P, Tsui AO: Individual, community and service environment factors associated with modern contraceptive use in five Sub-Saharan African countries: A multilevel, multinomial analysis using geographically linked data from PMA2020. PLoS One 2019, 14(6):e0218157.

38. Sultana A: Patriarchy and Women s Subordination: A Theoretical Analysis. Arts Faculty Journal 2010:1-18.

39. Caldwell JC, Caldwell P: The cultural context of high fertility in sub-Saharan Africa. Population and development review 1987:409-437.

40. Muteshi JK, Miller S, Belizán JM: The ongoing violence against women: Female Genital Mutilation/Cutting. Reproductive Health 2016, 13(1):44.

41. Stephenson R, Baschieri A, Clements S, Hennink M, Madise N: Contextual influences on modern contraceptive use in sub-Saharan Africa. Am J Public Health 2007, 97(7):1233-1240.

42. Pambè MW, Gnoumou B, Kaboré I: Relationship between women's socioeconomic status and empowerment in Burkina Faso: A focus on participation in decision-making and experience of domestic violence. African Population Studies 2014, 28:1146-1156.

43. Heckert J, Fabic MS: Improving data concerning women's empowerment in sub-Saharan Africa. Stud Fam Plann 2013, 44(3):319-344.

44. McMillan DW, Chavis DM: Sense of community: A definition and theory. J Community Psychol 1986, 14(1):6-23.

45. Women WCo, Nations U: Report of the Fourth World Conference on Women: Beijing, 4-15 September 1995: na; 1996.

46. Nations U: Report of the international conference on population and development. Cairo, September 1994:5-13.

\section{Tables}

Table 1: Constructs of women's agency derived from 12 DHS responses 


\begin{tabular}{|c|c|c|c|}
\hline Constructs & DHS questions & $\begin{array}{l}\text { Original categorization from } \\
\text { the DHS used in the PCA }\end{array}$ & $\begin{array}{l}\text { Scaled responses } \\
\text { used after PCA }\end{array}$ \\
\hline $\begin{array}{l}\text { Attitudes toward } \\
\text { domestic violence }\end{array}$ & $\begin{array}{l}\text { Is a husband justified in hitting/beating his wife in the following } \\
\qquad \text { situations? ( } 5 \text { responses }{ }^{\text {a }} \text { ) }\end{array}$ & $\begin{array}{c}1=\text { yes } \\
0=\text { no } \\
8=\text { don't know }\end{array}$ & $\begin{array}{l}1=\text { no } \\
0=\text { yes } \& \text { don't } \\
\text { know }\end{array}$ \\
\hline $\begin{array}{l}\text { Involvement in } \\
\text { decision-making }\end{array}$ & $\begin{array}{l}\text { Who usually has the final say in the family in the following decisions? } \\
\qquad\left(3 \text { responses }^{b}\right)\end{array}$ & $\begin{array}{c}1=\text { respondent alone } \\
2=\text { jointly } \\
4=\text { partner alone } \\
5=\text { someone else } \\
6=\text { other }\end{array}$ & $\begin{array}{c}1 \text { = jointly or } \\
\text { alone } \\
0 \text { = partner } \\
\text { alone; } \\
\text { someone else and } \\
\text { other }\end{array}$ \\
\hline $\begin{array}{l}\text { Freedom in seeking } \\
\text { medical services }\end{array}$ & $\begin{array}{l}\text { When you are sick and want to get medical advice or treatment, is } \\
\text { each of the following a big problem or not? (4 responses } 9 \text { ) }\end{array}$ & $\begin{aligned} & 1=\text { big problem } \\
2= & \text { not a big problem }\end{aligned}$ & $\begin{aligned} 1= & \text { not a big } \\
& \text { problem } \\
0= & \text { big problem }\end{aligned}$ \\
\hline $\begin{array}{l}\text { a If she goes out wit } \\
\text { b Decisions on famil }\end{array}$ & $\begin{array}{l}\text { telling him, neglects the children, argues with him, refuses sex, or b } \\
\text { sits, own health care, or household purchases } \\
\text { mission to go, money needed for treatment, distance to the health fac }\end{array}$ & food. & \\
\hline
\end{tabular}

Table 2: Factor loading of women's agency domains in Principal Component Analysis (PCA) before varimax rotation 


\begin{tabular}{|c|c|c|c|}
\hline \multirow{2}{*}{$\frac{\text { Reliability }}{\text { Women's agency }}$} & \multicolumn{3}{|c|}{ Factors loadings } \\
\hline & Gender equitable attitudes & Influence on decisions & Freedom in seeking healthcare \\
\hline \multicolumn{4}{|l|}{ Attitudes toward domestic violence } \\
\hline Goes out without telling him & 0.4440 & -0.0881 & -0.0951 \\
\hline Neglects the children & 0.4536 & -0.0946 & -0.1087 \\
\hline Argues with him & 0.4552 & -0.0581 & -0.1306 \\
\hline Refuses sex & 0.4087 & -0.0345 & -0.1354 \\
\hline Burns food & 0.3701 & -0.0859 & -0.0664 \\
\hline \multicolumn{4}{|l|}{ Participate in household decisions } \\
\hline Family visits & 0.1586 & 0.6136 & 0.1564 \\
\hline Own health care & 0.1500 & 0.5701 & 0.2019 \\
\hline Household purchases & 0.0980 & 0.3495 & 0.2463 \\
\hline \multicolumn{4}{|l|}{ Problems in getting medical help when sick: } \\
\hline Needs permission to go & 0.0799 & -0.2277 & 0.4930 \\
\hline Needs money for treatment & 0.0667 & -0.0601 & 0.3568 \\
\hline Prohibited by distance to health facility & 0.0973 & -0.2318 & 0.4412 \\
\hline Not willing to go alone & 0.913 & -0.1962 & 0.4984 \\
\hline Eigen values & 3.1 & 1.7 & 2.2 \\
\hline Variance explained (\%) & 25.7 & 18.5 & 14.0 \\
\hline
\end{tabular}

Table 3: Modern contraceptive prevalence in relation to women's agency,gender equality in communities, and demographic characteristics 


\begin{tabular}{ccccc}
\hline Characteristics & N & \% & Use (\%) & P-value \\
\hline Women's agency & N (4714) & & & \\
\hline Opposition to domestic violence & & & & \\
\hline No: Justification in some occasions (0-4) & 2040 & 43.9 & 26.0 & \\
Yes: Allows no justification (5) & 2674 & 56.1 & 34.4 & \\
Participation in household decisions & & & & 0.0001 \\
No: No participation (0) & 1903 & 39.1 & 26.5 & \\
Yes: Some or full participation (1-3) & 2811 & 60.9 & 33.5 & \\
Freedom in seeking healthcare & & & & \\
No: Problems in some situation(s) (0-3) & 3639 & 77.7 & 27.8 & \\
Yes: No problem (4) & 1075 & 22.3 & 41.0 & \\
\hline Community-level indicators of gender equality & N (573) & \% \& means & & \\
\hline
\end{tabular}

Violence and discrimination against women

\begin{tabular}{|c|c|c|c|c|}
\hline Acceptance of domestic violence & & 43.2 & & 0.0001 \\
\hline Low & 289 & 50.4 & 35.6 & \\
\hline High & 284 & 49.6 & 25.7 & \\
\hline Early marriage & & 46.9 & & 0.0001 \\
\hline Low & 298 & 52.0 & 37.8 & \\
\hline High & 275 & 48.0 & 23.8 & \\
\hline Genital mutilation & & 76.2 & & 0.0532 \\
\hline Low & 228 & 39.8 & 33.1 & \\
\hline High & 345 & 60.2 & 29.0 & \\
\hline Unpaid work & & 35.9 & & 0.0001 \\
\hline Low & 331 & 57.8 & 34.7 & \\
\hline High & 242 & 42.2 & 25.4 & \\
\hline Ideal number of children & & 5.5 & & 0.0001 \\
\hline Low & 291 & 50.8 & 38.7 & \\
\hline High & 282 & 49.2 & 21.8 & \\
\hline otion of women's rights and opport & & & & \\
\hline Assets ownership & & 39.5 & & 0.0784 \\
\hline Low & 301 & 52.5 & 32.4 & \\
\hline High & 272 & 47.5 & 28.9 & \\
\hline Secondary education & & 12.4 & & 0.0001 \\
\hline Low & 386 & 67.4 & 23.2 & \\
\hline High & 187 & 32.6 & 47.1 & \\
\hline Exposure to FP messages & & 60.1 & & 0.0001 \\
\hline Low & 269 & 47.0 & 22.8 & \\
\hline High & 304 & 53.0 & 39.2 & \\
\hline Contact with FP health worker & & 29.6 & & 0.2058 \\
\hline Low & 322 & 56.2 & 31.8 & \\
\hline
\end{tabular}



High
251
43.8
29.3

Demographic characteristics

\begin{tabular}{|c|c|c|c|c|}
\hline Household wealth & & & & 0.0001 \\
\hline Poor & 1516 & 33.9 & 19.2 & \\
\hline Middle & 906 & 19.0 & 21.8 & \\
\hline Rich & 2292 & 47.1 & 42.7 & \\
\hline Household residential area & & & & 0.0001 \\
\hline Urban & 1522 & 27.3 & 48.2 & \\
\hline Rural & 3192 & 72.7 & 24.2 & \\
\hline Women's age & & & & 0.0471 \\
\hline $15-24$ & 1162 & 25.0 & 27.5 & \\
\hline $25-39$ & 1900 & 40.7 & 32.0 & \\
\hline $40-49$ & 1652 & 34.3 & 31.6 & \\
\hline Women's education level & & & & 0.0001 \\
\hline No education & 3596 & 76.7 & 25.3 & \\
\hline Primary & 674 & 13.7 & 40.5 & \\
\hline Secondary \& Higher & 444 & 9.6 & 60.4 & \\
\hline
\end{tabular}

Table 4: Multilevel logistic modelling of empowerment, demographic factors and modern contraceptive use among women in-need 


\begin{tabular}{|c|c|c|c|c|c|c|}
\hline \multirow{2}{*}{$\begin{array}{c}\text { Regressions } \\
\text { Women's agency }\end{array}$} & \multicolumn{2}{|c|}{ Model 1} & \multicolumn{2}{|c|}{ Model 2} & \multicolumn{2}{|c|}{ Model 3} \\
\hline & aOR & $95 \% \mathrm{CI}$ & $\mathrm{aOR}$ & $95 \% \mathrm{CI}$ & $\mathrm{aOR}$ & $95 \% \mathrm{CI}$ \\
\hline \multicolumn{7}{|c|}{ Opposition to domestic violence (No) } \\
\hline Yes & $1.36^{* * *}$ & [1.16-1.60] & $1.25^{*}$ & [1.06-1.47] & 1.15 & {$[0.97-1.37]$} \\
\hline \multicolumn{7}{|c|}{ Participation in household decisions (No) } \\
\hline Yes & $1.30^{* *}$ & [1.11-1.53] & $1.21 *$ & [1.03-1.41] & 1.12 & {$[0.96-1.31]$} \\
\hline \multicolumn{7}{|c|}{ Freedom in seeking healthcare (No) } \\
\hline Yes & $1.62^{* * *}$ & [1.36-1.93] & $1.43^{* * *}$ & {$[1.20-1.71]$} & $1.29^{* *}$ & {$[1.08-1.54]$} \\
\hline
\end{tabular}

Community-level indicators of gender equality

Violence and discrimination against women

Acceptance of domestic violence (Low)
High
0.92
[0.76-1.13]
0.90
[0.74-1.10]

Early marriage (Low)

High

0.98

[0.79-1.21]

1.04

[0.84-1.28]

Genital mutilation (Low)

$$
\text { High }
$$

$1.25 *$

[1.03-1.52]

$1.25 *$

[1.03-1.52]

Unpaid work (Low)

$$
\text { High }
$$

0.92

[0.76-1.12]

0.97

[0.79-1.19]

Ideal number of children (Low)

$$
\text { High }
$$

$0.66^{* * *}$

[0.52-0.82]

$0.76^{*}$

[0.61-0.95]

\section{Women's rights and opportunities}

Assets ownership (Low)

High

[0.95-1.40]

$1.26^{*}$

[1.04-1.54]

Secondary education (Low)

$$
\text { High }
$$

$2.11^{* * *}$

[1.63-2.72]

$1.45^{* *}$

[1.08-1.64]

Exposure to FP messages (Low)

$$
\text { High }
$$

$1.51 * * *$

[1.24-1.85]

$1.33^{* *}$

[1.08-1.64]

Contact with FP health worker (Low)

$$
\text { High }
$$

1.07

[0.89-1.28]

1.10

[0.92-1.32]

Demographic characteristics

Household wealth situation (Poor)

$$
\begin{aligned}
& \text { Middle } \\
& \text { Rich }
\end{aligned}
$$

1.13

[0.90-1.41]

$1.79 * * *$

[1.44-2.22]

Household residential area (Rural)

Urban

Women's age (15-24)

$$
\begin{aligned}
& \text { 25-39 } \\
& \text { 40-49 }
\end{aligned}
$$

Women's education level (No education) 
Model statistics

Log likelihood

Chi-square
$-2783.11$

60.4
$-2708.2$

240.7
$-2657.3$

339.6

Comparison with previous model

Chi-square

Degrees of freedom

$149.82^{* * *}$

9

$101.8^{* * *}$

Random variance

ICC Null $=0.20$ 95\%CI [0.16-0.24]

Variance between clusters

0.17

0.70

[0.14-0.22]

0.10

$[0.54-0.91]$

0.38

$[0.08-0.14]$

0.09

[0.27-0.53]

0.33

$[0.07-0.13]$

[0.23-0.49]

Null: 0.82 95\%CI [0.64-1.05]

PVC (\%)

Note: $\mathrm{aOR},=$ Adjusted Odds Ratios, $\mathrm{CI}=$ Confidence Interval, ICC = Intra-class correlation, PVC = Proportional Variance Change; $*$ p<0.05; ** $\mathrm{p}<0.01 ; * * * \mathrm{p}<0.001$

\section{Figures}

Community-level indicators of gender equality

Violence and discrimination against women

(Domestic violence, early marriage, female genital mutilation, unpaid employment);

Women's rights and opportunities (assets ownership, years of education, ideal number of children, exposure to FP messages, contact with FP health worker)

Women's agency in household matters Attitudes toward domestic violence; Influence on household decisions; Freedom in seeking healthcare.

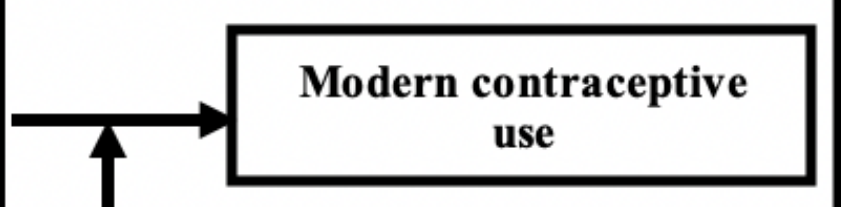

Demographic factors

Household (wealth/residence)

Women (age and education) 


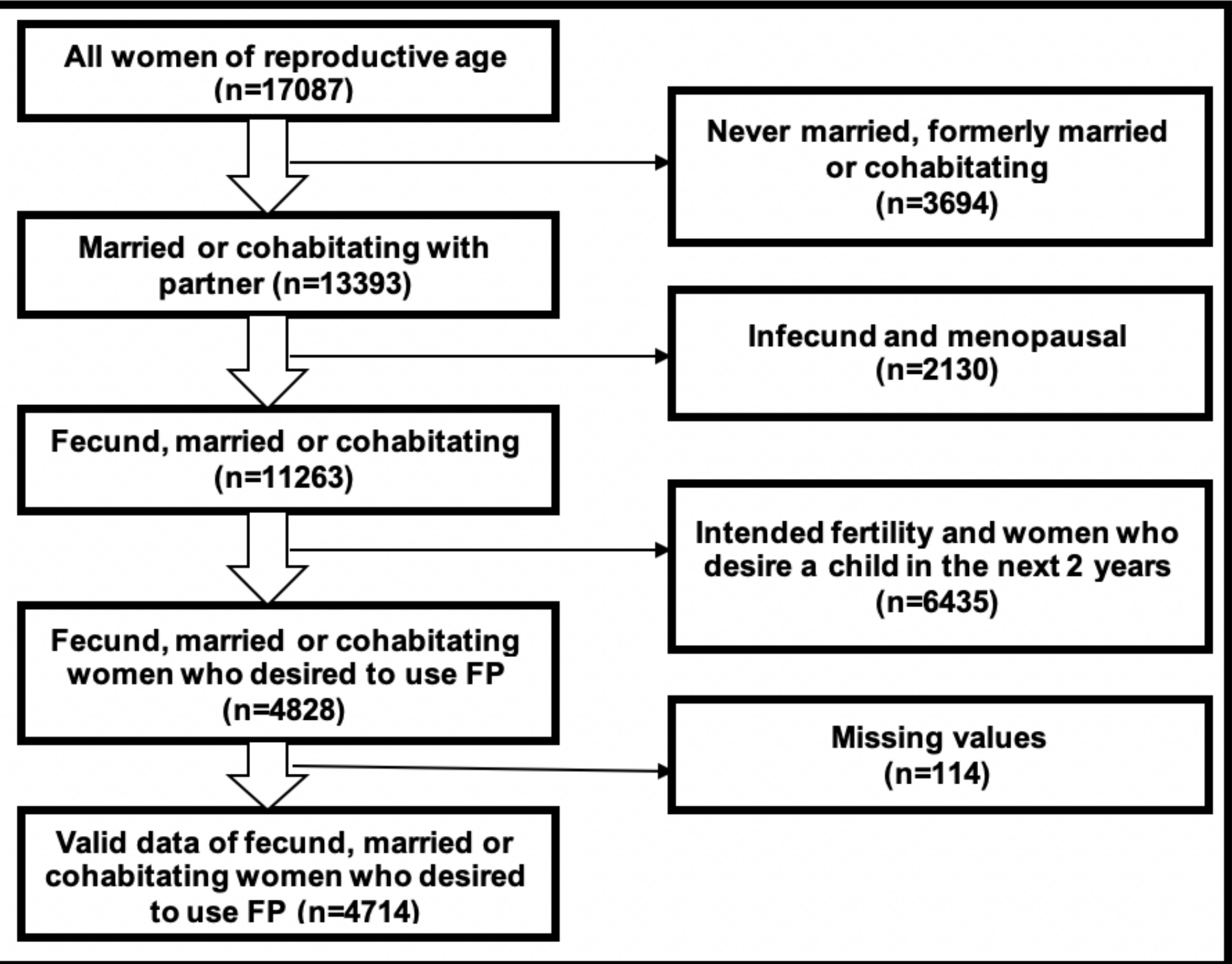

Figure 2

Flow chart of sample selection 